\title{
La mirada de las mujeres: otros patrimonios, otro turismo
}

\author{
Paloma González Marcén | Universidad Autónoma de Barcelona
}

URL de la contribución <www.iaph.es/revistaph/index.php/revistaph/article/view/3744>

La dimensión estructural de las mujeres como creadoras y mantenedores de los vínculos culturales dentro y entre las comunidades comienza a emerger como una variable fundamental para la definición de nuevos conceptos y prácticas relacionadas con el patrimonio. De hecho, hasta ahora la noción dominante y sancionada oficialmente de lo que se ha considerado patrimonio se ha establecido en relación con las áreas de expresión cultural del poder masculino, de un espacio público que con frecuencia viene definido por la exclusión de las mujeres y los niños, y de prácticas culturales excepcionales. No es de extrañar que esta preferencia se asocie a la arraigada dicotomía entre la alta cultura y la cultura popular y, del mismo modo, con la valoración diferencial que existe entre el patrimonio singular y las prácticas culturales de la vida cotidiana.

La crítica del feminismo a esta noción de patrimonio ha tenido hasta ahora poco impacto en las políticas y prácticas de gestión del patrimonio; sobre todo porque se ponen en duda, radicalmente, los criterios existentes sobre el valor social del patrimonio. Sin embargo, las experiencias y propuestas que están surgiendo muestran un concepto de patrimonio que retoma la herencia cultural de las mujeres, que fortalece el potencial cohesionador y creativo de sus prácticas asociadas, y que se centra en la vida cotidiana y las experiencias de vida de las comunidades. Estas propuestas comienzan a expresarse ya de formas y en contextos diversos, desde relecturas en instituciones patrimoniales tradicionales, como puedan ser los museos, hasta proyectos de asociaciones de mujeres que visibilizan, reivindican y ponen en valor sus patrimonios individuales y colectivos (CLARKE; DUNPHY; WRIGHT, 2015).

Si cruzamos la perspectiva de visibilización y empoderamiento con la variable de su dimensión turística surge una aproximación más compleja. El auge del turismo cul- tural ha venido emparejado con la noción de patrimonio monumental y androcéntrico que ha ocultado y minimizado el patrimonio en clave de género. Por tanto, no se trata ya sólo de repensar el modelo patrimonial, sino de concebir nuevos modelos turísticos fundamentados en esos otros valores a los que hacía referencia al principio de este texto. Un magnífico ejemplo de este otro turismo podemos encontrarlo en la puesta en valor de la denominada Maternidad de Elna, una institución creada en 1939 por la enfermera Elisabeth Eidenbenz para atender a las madres del campo de concentració de Argelès-surMer de la Guerra Civil española, cuya sede fue restaurada y abierta a las visitas públicas en 2013. Ejemplos de un turismo patrimonial de este tipo que se conecta con otros referentes históricos y valores sociales empiezan a aparecer en diferentes partes del mundo, como el Cascades Female Factory en Tasmania, un correccional para mujeres del siglo XIX y actualmente incluido en la lista de Patrimonio Mundial de UNESCO (CASELLA 2001), o el proyecto para la recuperación de la historia del Phyllis Wheatley Home for Girls de Chicago (AGBEDAVIES, 2010).

Si pasamos del patrimonio tangible al patrimonio intangible también el fenómeno del turismo rural o el ecoturismo puede ofrecer oportunidades para impulsar procesos de patrimonialización vinculados a las prácticas culturales femeninas. Una de las dinámicas que se está viviendo en muchas comunidades rurales es la toma de conciencia de asociaciones de mujeres de su papel en el mantenimiento de los vínculos culturales que dotan de identidad y cohesión a la propia comunidad. Muchas de ellas están llevando a cabo proyectos a pequeña escala, pero con fuerte impacto local, que, reformulando las tradiciones y prácticas culturales comunitarias, van dirigidos tanto a la reivindicación de un papel activo y autónomo de las mujeres en la gestión pública como al mantenimiento de las señas de identidad locales que propician un valor 


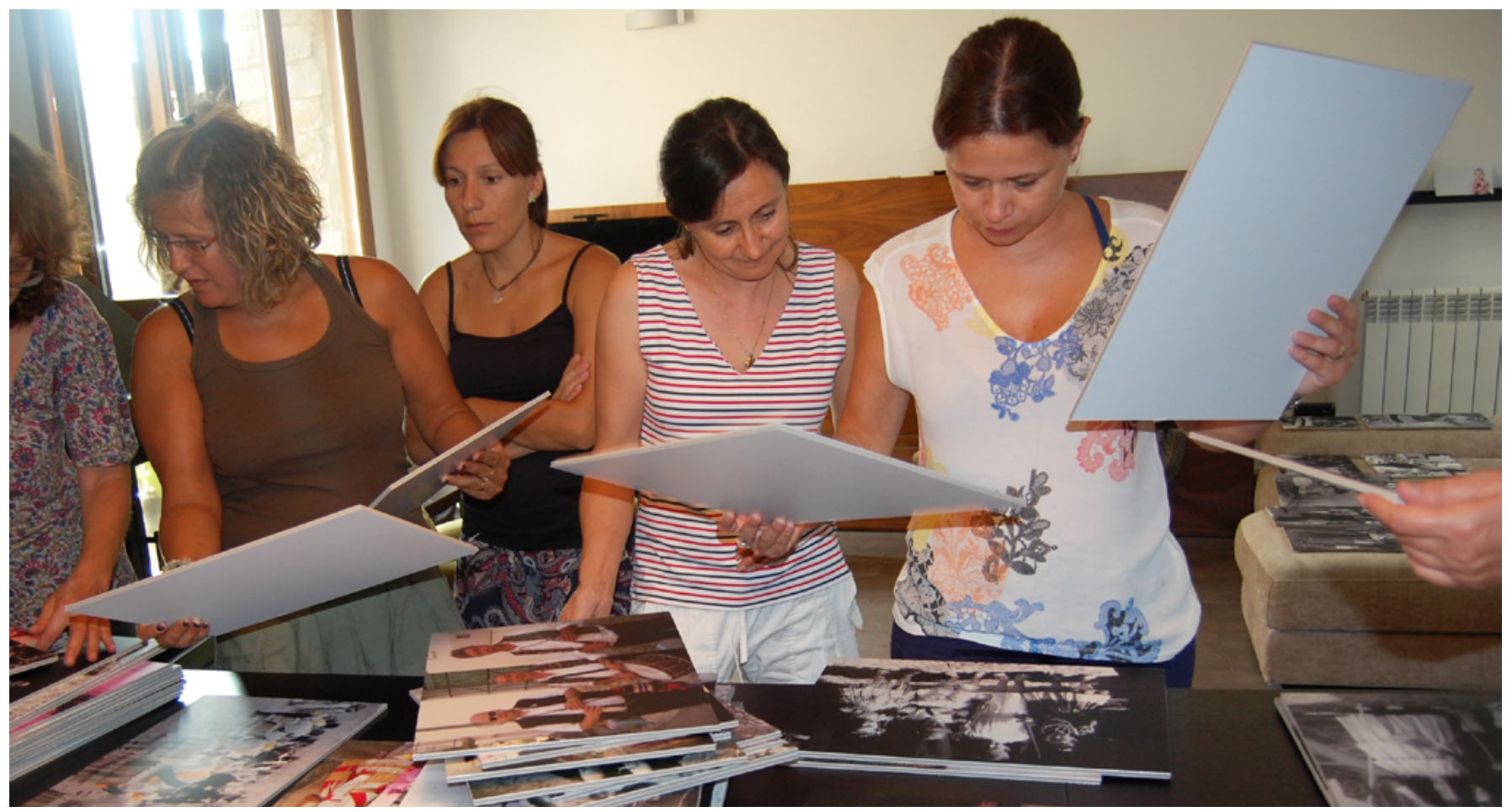

Asociación de mujeres de Sorita (Castellón) | foto Paloma González Marcén

añadido a las ofertas turísticas (LOZANO; SÁNCHEZMUROS; JIMÉNEZ RODRIGO, 2013).

Sin embargo, es cierto que el mantenimiento de tradiciones y prácticas intangibles también puede convertirse en freno para avanzar en la equidad de género y en la inclusión en la sociedad contemporánea, así como perpetuar situaciones de desigualdad simbólica y económica (MOGHADAM; BAGHERITARI, 2007). Por lo tanto, un desafío cultural principal para las mujeres, en su papel de portadores patrimoniales primarias, es recrear experiencias y prácticas de sus identidades y conocimientos, manteniendo su contenido de cohesión y de creación, como plataforma de participación, empoderamiento y sostenibilidad.

\section{BIBLIOGRAFÍA}

- AGBE-DAVIES, A. S. (2010) Archaeology as a Tool to Illuminate and Support Community Struggles in the Black Metropolis of the Twentieth and Twenty-first Centuries. Public Archaeology, 9(4), 2010, pp. 171-193

- CASELLA, E. C. (2001) To watch or restrain: Female convict prisons in 19th-century Tasmania. International Journal of Historical Archaeology, 5(1), 2001, pp. 45-72

- CLARKE, R.; DUNPHY,P.; WRIGHT,P. (2015) Photoparshiya - Discursive Assemblages in an International Women's Centre. En Proceedings of the 2nd Biennial Research Through Design Conference, 25-27 March 2015. Cambridge, UK, 2015

- LOZANO, S.; SÁNCHEZ-MUROS, P.; JIMÉNEZ RODRIGO, M. ${ }^{a}$ L. (2013) Mujeres rurales y participación social: análisis del asociacionismo femenino en la provincia de Granada (España). Cuadernos de Desarrollo Rural, 10 (72), 2013, pp. 223-242

- MOGHADAM, V.; BAGHERITARI, M. (2007) Cultures, conventions, and the human rights of women: Examining the convention for safeguarding intangible cultural heritage, and the declaration on cultural diversity. Museum International, 59(4), 2007, pp. 9-18 